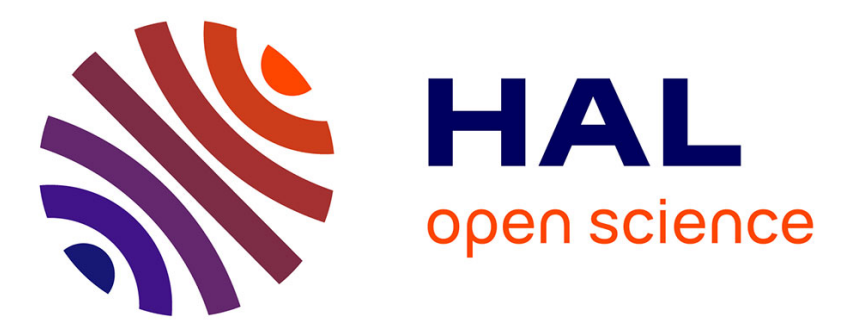

\title{
A lifespan perspective on transitions during a top sports career: A case of an elite female fencer
}

\author{
Nadine Debois, Aurélie Ledon, Cécile Argiolas, Elisabeth Rosnet
}

\section{To cite this version:}

Nadine Debois, Aurélie Ledon, Cécile Argiolas, Elisabeth Rosnet. A lifespan perspective on transitions during a top sports career: A case of an elite female fencer. Psychology of Sport and Exercise, 2012, 13 (5), pp.660-668. 10.1016/j.psychsport.2012.04.010 . hal-01828652

\section{HAL Id: hal-01828652 \\ https://hal-insep.archives-ouvertes.fr/hal-01828652}

Submitted on 3 Jul 2018

HAL is a multi-disciplinary open access archive for the deposit and dissemination of scientific research documents, whether they are published or not. The documents may come from teaching and research institutions in France or abroad, or from public or private research centers.
L'archive ouverte pluridisciplinaire HAL, est destinée au dépôt et à la diffusion de documents scientifiques de niveau recherche, publiés ou non, émanant des établissements d'enseignement et de recherche français ou étrangers, des laboratoires publics ou privés. 


\title{
A Lifespan Perspective on Transitions during a Top Sport Career:
}

\author{
A Case of an Elite Female Fencer \\ Nadine Debois a, Aurélie Ledon ', Cécile Argiolas c, Elisabeth Rosnet ${ }^{\text {a }}$ \\ a National Institute of Sport, Expertise and Performance, Paris, France \\ b Ardenne-Champagne University, Reims, France \\ c Sport Departmental Direction, Foix, France \\ Article publié dans : Psychology of Sport and Exercise (ISSN 1469-0292), 2012, vol. 13, n5, pp. 660-668
}

(doi:10.1016/j.psychsport.2012.04.010)

\section{Introduction}

In an elite sport career, the Olympic Games (OG) embody the outcome most athletes strive for. It often begins as a dream, which then takes shape as athletes improve their performance, until it becomes the main goal. Participation alone does not usually fulfil higherlevel athletes' aspirations. Some of them aim for the Olympic title whereas others aim to win a medal or at least a place in the finals. Whatever their ambition, they all want to be in a position to say to themselves after the Olympic event: "I really gave it my best that day".

Satisfaction with their sport career and the feeling of achievement elite athletes gain from it rest, then, to a large extent, on the concomitance between the period during which athletes are in a position to give their very best and the Olympic four-year term. This harmonious concomitance does not only depend on the quality of sport preparation. It is developed through trajectories of life and transitions during the sport career, including sporting transitions, as well as academic, professional, social and personal transitions (Wylleman \& Lavallee, 2004; Wylleman, Alfermann, \& Lavallee, 2004).

Schlossberg (1981) described transition as "an event or a non-event which results in a change in assumptions about oneself and the world and thus requires a corresponding change in one's behaviour and relationships" (p.5). In the sports domain, Sinclair and Orlick (1993) distinguished positive transitions, which are negotiated by athletes without particular assistance, and crisis transitions for which the athletes need specific psychological support. Stambulova (2000) described three kinds of coping strategies chosen by athletes facing a 
crisis situation: (a) rejection strategy, which involves avoiding the situation, withdrawing from the activity or breaking a relationship; (b) acceptance strategy, which involves staying in the situation and accepting a compromise to adapt to it; and (c) fighting strategy, which involves changing both the athlete's attitude toward the situation and the situation per se.

Throughout their sporting careers, athletes go through different stages in the development of their expertise (Bloom, 1985; Côté, 1999; Stambulova, 2000). This career is punctuated by transitions specific to the sporting career (e.g., Stambulova, 2000) or relating to the end of the career (e.g., Taylor \& Ogilvie, 1994), as well as to other elements of the athletes' life, such as their personal, educational or vocational development, or even their social and affectionate life (e.g., Sinclair \& Orlick, 1993; Wylleman \& al., 2004). Wylleman and Lavallee (2004) suggested grouping all forms of transitions (athletic and non-athletic) susceptible to punctuate the course of an athlete's life, and to classify them into two large categories: (a) nonnormative transitions, and (b) normative transitions. The non-normative transitions result from important, unplanned events in the life of the individual, which take place in an unforeseen and involuntary manner (Schlossberg, 1984). In sports, these transitions can be brought about by a season-ending injury, the loss of a coach, or an unanticipated rupture within the team. They also include non-events (i.e., awaited or desired events that do not occur), such as not been integrated into the first team or failure in the selection for the OG. Normative transitions are those transitions that correspond to the "normal" passage from one stage to another. They form part of a definite change in events or biological, social and emotional changes related to age (Baltes, 1987), in general terms, the process of socialization (Wapner \& Craig-Bay, 1992), and to the organizational context in which the individual is involved (e.g., school, family). Therefore, they are generally predictable, and can be anticipated in the planning and organization of the athlete's career (e.g., Schlossberg, 1984; Sharf, 1997; Wylleman \& Lavallee, 2004). Wylleman et Lavallee (2004) distinguished four 
categories of normative transitions all characterized as normal (Petitpas, Champagne,

Chartrand, Danish, \& Murphy, 1997) or that can be planned (Sinclair \& Orlick, 1993): (a) transitions relating to the sporting career, (b) transitions relating to psychological development, (c) transitions relating to social development, and (d) transitions relating to educative and professional development. Furthermore, several studies emphasized that career paths which lead to excellence are not linear (e.g., Abott, Button, Pepping, \& Collins, 2005; MacNamara, Button, \& Collins, 2010; Ollis, MacPherson, \& Collins, 2006). Of course all career paths include the main stages (e.g., initiation, development, specialisation, mastery) commonly described in studies relating to the development of expertise (e.g., Bloom, 1985; Côté, 1999; Stambulova, 1994; Stambulova, Alfermann, Statler, \& Côté, 2009). Nevertheless, each trajectory is singular, consisting of micro-stages peculiar to each one (e.g., injury, change of performance context), and which create wave-like progress towards excellence. With such an uncertain path, regular psychological follow up appears useful to help athletes successfully negotiate sensitive transitions, especially as it provides them with an opportunity to talk about their life, to communicate a sense of their previous experiences to others and, in this way, to maintain a coherent identity and sense of self (e.g., Carless \& Douglas, 2008; Crossley, 2000; Douglas \& Carless, 2009).

Durand-Bush and Salmela (2002) identified three categories of factors supporting the development of talent in highly successful athletes (i.e., Olympic champions and/or World champions at least once during their career), as well as their constancy at a very high level: (a) factors relating to the athlete's human environment (i.e., parents, coach, technical coaching staff); (b) personal factors (i.e., personal characteristics, decision to continue studies); and (c) factors relating to investment in sport (i.e., deliberate practice, implementation of mental strategies and organisation). In addition, sport enjoyment and satisfaction with sport improvement seem to be important elements of persistence in practice (Côté \& Hay, 2002). 
For their part, Palmer and Leberman (2009) studied the particular case of motherhood during female elite sports career. They pointed out the benefits of motherhood to sporting ambitions. For example, becoming a mother contributed to changing athletes' perspective on life, due to the need to negotiate multiple identities and roles and to find time/space management strategies to reconcile the constraints of motherhood and elite sport requirements. It also enriched their sport experience through higher resilience and adaptability when dealing with the challenges of elite sport. These results testify to the importance of widening the search related to the conditions of sporting success to other factors which do not relate directly to training in sport.

In that context, the present paper sets out the case of an elite athlete who followed the Olympic route twice and participated once. The purpose of this contribution was to explore, through a holistic lifespan approach, how this athlete dealt with key events and transitions in her sports career as well as in other domains of life.

\section{Method}

\section{Participant}

The participant in this study was Francine (alias), a female elite fencer. Francine began to practice foil in a club at the age of 8 and entered the junior national foil-training centre aged 18. She achieved her first selection for the World Championships at 19 years old. A year later, she entered the elite foil-training centre. There, she achieved poor sport results and decided to withdraw from fencing at the age of 22 . Back home, she began sabre in a club and had very soon achieved promising results. At 23 years old, she entered the elite sabre-training centre. She won a silver medal at the European Championships. At 25 years old, Francine left the training centre to live with her partner. At the age of 26, she won the European title, a bronze medal at the World Championships and three World Cup events. When she was 28 years old, 
she ended thirteenth at the OG. She then took a break to have a baby. She returned to training at the age of 29 . Between the ages of 30 and 31 , she won a team gold medal in each of the two World Championships preceding the OG. At 32 years old, Francine failed to qualify for the OG and decided to end her fencing career. She had a second baby 10 months after retiring from elite sport.

Regarding her educational and vocational development, Francine began academic studies in geography at the age of 19 but ended her studies prematurely four years later. At the age of 24, she gained a coaching diploma in fencing. At 25 years old, she passed a police training college entry examination. She studied there for two years and became a policewoman at 27 years old. A year later, she failed a competitive examination for a sport education course but applied again and was successful at 30 years of age. She began work as a trainee sport ministry officer at 31 years old and got tenure a year later.

\section{Procedure}

A narrative approach was adopted, consisting of reconstructing and then analysing the athlete's story with data collected from a retrospective in-depth interview, as well as from handwritten notes taken by the fourth author during assessment, follow-up and psychological counselling interviews over a period of fourteen years.

The fourth author, who knew the participant in her role as a sport psychologist working for the fencing federation, contacted her and explained the aim of the present study. The participant was asked for her permission for her personal data to be used in a narrative and content analysis. The participant agreed. To ensure confidentiality, pseudonyms have been used throughout this paper for people as well as for living and training locations, and the years of the Olympic Games concerned have not been mentioned.

\section{Data collection}


Four types of data were gathered: (a) qualitative data issued from a retrospective indepth interview conducted at the end of Francine's sports career, (b) qualitative data issued from three psychological assessment interviews, (c) handwritten notes taken during six follow-up interviews and, (d) handwritten notes taken during 52 psychological consultation interviews.

The first two authors, who are experienced in qualitative methods as well as in elite sport, conducted an in-depth interview with Francine. Each part of the interview lasted about one and a half hours and was audio-recorded with the agreement of the athlete. The first part of the interview aimed to set out the framework of the athlete's life using a chronological grid based on the developmental model presented by Wylleman \& Lavallee (2004). The second part of the interview invited the athlete to outline the main elements she perceived as having played a significant role during the course of her life. Afterwards, the chronological grid built up during the first interview was presented to the athlete whereby she was invited to identify the main stages in the course of her life and the key transitions from one stage to the following one, including those within each stage. Each stage and key transition was then, in chronological order, recounted in depth.

The fourth author, with high experience both in research and in applied sport psychology, conducted psychological assessment interviews as well as follow-up interviews within the context of the fencing federation which requires elite athletes to undergo a psychological assessment including tests, self-assessment questionnaires and an interview (cf. Rosnet, 2005; Rosnet, Le Scanff \& Heuzé, 2003). The aim of the assessment is to have sufficient knowledge about the applicants to be able to plan their life inside the training centre in the best way (Rosnet, 2005). During their time within the training centre they can, if they choose, meet the federal psychologist for follow-up interviews. In this context, Francine had three psychological assessments: (a) upon entry to the junior foil-training centre at 18 years old, (b) 
upon entry to the elite foil-training centre at the age of 20, and (c) when living in the elite sabre-training centre at 23 years old. The psychological assessment interview lasting about one and a half hours aimed to qualitatively assess the likelihood of Francine adapting to life within the sport centre in terms of sports as well as educational, family and social aspects. In the same way, follow-up interviews were planned to check the adaptation of Francine to the different aspects of life within the training centre (i.e., sport performance, school performance, life in the sports group, life in the training centre and family life). Francine had 3 follow-up interviews during her time within the junior foil-training centre, and three followup interviews during the first year of her time within the elite foil-training centre.

Finally, the fourth author conducted psychological consultation interviews, at Francine's request, as follows: 16 interviews during the 16 months preceding Francine's Olympic Games participation and 36 interviews during the three years preceding the following Games. Each interview lasted between one hour and one and a half hours. Psychological consultation interviews included both mental preparation (e.g., mental skill development for performance) and psychological follow-up focused on personal development and life management. Data collected for the present study were those related to Francine's narratives about her personal development and life management.

\section{Data analysis}

Both parts of the retrospective interview were transcribed verbatim from the audiotape. The first two authors read the interview transcript several times and then independently coded the interview texts to identify meaningful pieces of information (i.e., units of meaning) according to the purpose of the study (i.e., the nature of transitions and characteristics of life elements during an elite sports career). At this stage both authors compared and discussed the codes until consensus was reached. The comparison among the investigators' encoding was made by dividing the number of congruencies among the 
investigators by the number of pieces of raw data that were encoded (Thomas \& Nelson, 1996). The results showed $73.94 \%$ agreement. The next step consisted of extracting the main stages and key transitions identified by the athlete as significant in the course of her life. Units of meaning for each stage and key transition were subsequently compared and grouped together according to common features into increasingly complex categories.

Content analysis was done on 156 sheets of double-sided, handwritten notes from follow-up and psychological interviews to reduce a large body of qualitative information to a smaller one specifically related to Francine's narrative about herself and her life. The first and fourth authors initially read the sheets separately, then discussed them to reach consensus on data to collect. Finally, sections or words belonging to stages and transitions identified through analysis of the retrospective interview were examined in detail and coded in units of meaning in the same way as data from the retrospective interview.

\section{Results}

Data analysis yielded 523 units of meaning describing the athlete's life during her sports career. Francine perceived three key stages: (a) a stage of equilibrium between her family life, sports and studies including the first ten years of her fencing practice; (b) a stage of priority given to her sports career during the following seven years; and (c) a stage of stability due to being with her partner during the last eight years of the sport career.

She also distinguished 11 main transitions which she believed played a key role during the course of her life and of which nine related directly to her sports career, one to her education and one to her personal life. The nine sports transitions consisted of four linked to a change of training structure, two to good sports results, two to sports saturation, and one transition was linked to a need for achievement in sport. It should be noted that the transition relating to education was described in terms of its impact on the organisation of sports training. Table 1 summarises the key stages and transitions identified by the athlete. 
The findings are presented chronologically through stages and transitions emerging from the athlete's narrative during the retrospective interview.

\section{Stage of equilibrium between family life, sports and studies}

In this stage, Francine described two main transitions: (a) her first medal in a national competition, and (b) her decision to enter the junior foil-training centre.

\section{Medal achievement in a national youth championships (14 years old)}

Francine began foil at the age of eight. She practiced for fun and leisure until she won a medal at the national 'minime' (i.e., 14 and 15-year old fencers) championships. This result made her change her goals. She became aware that she liked winning and dreamed of one day participating in a World Championships. From then on, she trained more and with more involvement.

\section{Entering the junior foil-training centre (18 years old)}

Francine noted that her progress in foil was tending to stagnate due to a lack of opponents in training sessions. Following the advice of a regional coach, she applied for acceptance at a training centre. Francine was very motivated. She associated entering a training centre with accessing high level sport, as the following excerpt attests: "I really felt like I was discovering high level sport, with new training exercises, daily training, and the opportunity to dream of achieving something. That is it. It gave me the opportunity to dream".

An initial psychological assessment was conducted four months before entry. The assessment interview indicated that Francine was motivated, with a lot of energy, and very determined to try hard, even leaving the family home where she was happy, to try to access the top level in fencing. The assessment concluded she had very good potential for adapting to the training environment, if energy was correctly oriented towards the task.

\section{Stage of primacy to sport career}


This stage began when Francine entered the junior foil-training centre and ended when she moved from the elite sabre-training centre to live with her partner. During this stage, Francine distinguished four main transitions related to: (a) entry into the elite foil-training centre, (b) her decision to withdraw from fencing, (c) entry to the elite sabre-training centre, and (d) high sport results.

Two months after her entry into the junior foil-training centre, Francine had a followup interview. She described a positive transition with both sport and social integration going well. Motivation, qualitatively assessed during the interview, was high and Francine looked determined. Another interview was conducted 5 months later. Francine had been selected for the World Championships and was very pleased about that, saying that "I've learned faster than expected".

\section{Entering the elite foil-training centre (20 years old)}

Given her promising sport results, Francine was invited to join the elite foil-training centre. At first she worried about having to go there because of both her satisfaction with her current training conditions (i.e., quality of the structure, good relationships with the coach and teammates) and her apprehension at having to live $900 \mathrm{~km}$ away from her home and family. But she knew that she had to go there if she wanted to continue in elite sports. In the end she decided to favour her sports career project: "After some time I took the decision to go to the elite training centre because I knew that otherwise I would have to withdraw from elite sports, whereas I really wanted to continue".

A psychological assessment was conducted two months before Francine's entry to the elite foil-training centre. During the interview, Francine appeared very determined to move from the junior foil-training centre to the elite foil-training centre. She pointed out that she had organised the transfer from her former university to the new one and had prepared for her integration with the new training group very carefully, from a material as well as a 
relationship point of view. Retrospectively, Francine confirmed: "I arrived in the training centre in the best of moods. I was very motivated especially as everything had gone smoothly in the previous training centre".

Three months after her entry to the centre, a follow-up interview indicated that Francine faced some stress in competitions. A short period of mental preparation was initiated. Five months later, she said that she now had a better feeling during competitions, and felt considerable pleasure and that she believed she had found a structured way to approach competition. She also mentioned relationship difficulties (i.e., misunderstandings, conflicts) and disagreements about the organisation of training. During the following year, Francine avoided meeting the psychologist. Retrospectively, she described experiencing a transition crisis accompanied by distress, injuries, and dissatisfaction with education, due to disparities between programmes from her former university and the new one, and an inability to adapt to the cold climate. She pointed out: "I withdrew into myself. I had the opportunity to talk about that with the psychologist who came regularly to the training centre and knew me quite well. I could have contacted her but I was not ready for that. I was really turned in on myself’.

\section{Decision to withdraw from elite foil-practice (22 years old)}

Francine decided to leave the elite foil-training centre to go back home. She said: "I was weary of the high level training system. I no longer enjoyed myself when fencing. I no longer wanted to fight in competitions." However, at the advice of a friend, she started sabre:

Sabre attracted me at once. It was a young specialty for women. I had to learn new techniques and those immediately suited me. It was just what I was looking for. From then on, I put a lot into it, for one reason because it suited me but also, I can't deny it, because, in this way, I worked out the frustrations from my elite foil-training centre experience. 
Francine took up competition and achieved high results very quickly. The fencing federation invited her to join the new elite sabre-training centre. The following excerpt illustrates her state of mind:

I had decided that I would not become involved in elite sports again and that I would never go back to an elite training centre, never! When the federation asked me to enter the elite sabre-training centre, I said no. Finally, my coach convinced me to accept, but it took a long time and many discussions. It took me one and a half months to say, "Ok, I understand, I am going to agree to go there, I am going to try the adventure".

\section{Entering the elite sabre-training centre (23 years old)}

Retrospectively, Francine described the transition to the elite sabre-training centre as positive. In the beginning, she found it difficult to adapt to the structure but she still enjoyed the extensive training in sabre and learning new techniques as well as tactics. She also loved the physical preparation based on team sports, sprints and other activities involving strenuous effort. The atmosphere within the group was also very motivating on account of both the harmony with teammates and the prospect of sabre for females being included in the Olympic Games. During that period, she withdrew from her academic studies in geography and gained a diploma in coaching fencing. Withdrawal from her studies was prompted by the difficulties posed by having to change university (i.e. three universities) every time she moved from one location to another:

It was difficult for me because of the different universities, all run in different ways, with different programmes and different levels of adjustment for elite athletes. I was tired of having to validate new units each time. I tried distance learning for a year but it didn't work. I decided to withdraw from my geography studies and to take a course in coaching fencing because it was the only thing I thought I could do well.

\section{Excellent sport results (24 years old)}


Francine gained very good results, which made her start to enjoy elite competition again:

In my first year at sabre, I achieved an individual silver medal in the European

Championships and a few months later a team silver medal in the World Championships.

From then on, I continued getting results in table $8^{1}$ or podiums. That made me like competition again.

After these results Francine participated in a systematic psychological assessment. During the assessment interview, she emphasised her satisfaction at being in the training centre.

\section{Stage of stability due to living with her partner}

This stage began with Francine's decision to live outside the training centre and ended with the termination of her sports career. Francine distinguished five transitions: (a) moving in with her partner, (b) entry to police training college, (c) coming back to train full-time in the elite sabre-training centre, (d) sport saturation, and (e) coming back to elite sports to prepare for the next OG.

\section{Moving in with her partner (25 years old)}

Two years after her entry to the elite sabre-training centre, Francine decided to live outside the structure with her partner. At that point she felt she had a good balance between her sports career project and her personal and emotional well-being, despite the inconvenience of travelling back and forth from home to the structure every day. During that period, she decided to secure her vocational future with state employment. She entered the police training college competitive examination and was successful. Retrospectively she said:"I applied for this examination after becoming aware that if I was seriously injured and forced to withdraw from elite sport, I had no way to earn my living. I just wanted to get a professional job".

\section{Entering the police training college (26 years old)}

\footnotetext{
1 "Table 8" in fencing competitions corresponds to the quarterfinal of the direct elimination phase.
} 
When Francine joined the police training school, she could no longer train twice a day in the elite sabre-training centre because of the distance between the school and the training centre. So she had to reorganise her training. She found a solution that suited her very much, combining daily training in the elite sabre-training centre with other trainings in a club. With this routine, her daily rhythm was very intensive, starting by waking up at $6 \mathrm{~h}$ and returning home at about $22 \mathrm{~h}$, with a lot of competitions at week-ends. After a year of such an intensive rhythm: "My body was so exhausted that I got a serious injury".

During this period, she won the individual title at the European Championships and an individual bronze medal at the World Championships. She then won three World Cup events in a row. After a $17^{\text {th }}$ place in the following cup event, she asked for a regular psychological follow-up. From that time, psychological assistance consisted of individual interviews according to the rhythm of competitions, at least once a month for five years. The reason Francine gave for asking for a psychological follow-up was to improve her feeling of control. She felt very good during her successful competitions but with no feeling of control. She wanted to better understand and control what she did to win and how she did it. She also felt that her results had exceeded her ability, saying that beforehand, she could not even have imagined that she would be able to win a World Cup event. Moreover, as the current national leader, a former world champion, was tending to show a decrease in performance, Francine was becoming the new leader. She felt strong pressure on her for the following European and World Championships due to her sensitivity to what others would say and think about her. The following excerpt illustrates Francine's state of mind: “I don't like having to live up to people's expectations. I don't understand why they are asking me to win so much. Maybe it's because (x) is not winning any more". Her main goal was now Olympic qualification.

Returning to full-time training in the elite sabre-training centre (27 years old) 
A year before the Olympic Games, which coincided with the end of police training college, Francine was given a special statute with a salary as a police officer but for full-time training. She went back to training full-time in the elite sabre-training centre. It took her some time to adapt: "When I came back to the elite centre, it was tough. I had to readapt to the system although I had become used to being autonomous. I had to get back into the environment. It wasn't easy.”

Francine knew that the Olympic season would be very tense due to the competition for Olympic qualification. She used most of the October-December period, when there is no international competition, to concentrate on herself, to adopt a healthier lifestyle (e.g., balanced diet, balanced sleep), to become more autonomous, not needing the coaches' instructions (e.g., taking initiative) and to develop her own way of fencing. This period ended with an individual national title. In a debriefing after the October-December period, Francine reported that she had felt very good during the event, using her new strategy, then analysing what she did. She had a stronger feeling of control than before. She also felt that her autonomy from the coaches and other fencers helped her to be more dispassionate, clear and objective.

During the OG qualification period (January-March), which is devoted to competitions, psychological follow-up only consisted of slight adjustments to the work under way. Francine labelled her stress as maximum during this period and felt that she needed to improve her coping strategies, concentrating even more on herself. Despite an injury at the beginning of March, Francine succeeded in qualifying for the OG in the final qualifying event.

The April to OG period began with rest and a strong feeling of relief for having achieved qualification. It also included reflection about the future. Francine planned to keep competing for two more years after the OG. As she was unsatisfied with her police job, she planned to undertake sport studies immediately after the OG. She wanted to enrol in a specific 
educational course reserved for elite athletes. With this aim, in April she applied for the course but failed to be selected. She was very disappointed about that. Retrospectively, she described her experience as follows: "They prevented me from enrolling in this sport education course, telling me that, as I had already secured a job as a policewoman, I did not need to enroll in this course. I really felt a tremendous sense of injustice!”

Moreover, Francine noticed that the climate had changed within the training group, due to the Olympic challenge:

We were in competition daily. There was a lot of pressure because it was the first time that female sabre was present in the Olympics and qualification could only be obtained through individual international rank. We had to be in the top 8 international athletes to qualify. We then had to fight throughout the year to stay amongst the top 8 . It was psychologically hard. It was exhausting. It lasted 12 months and we finished exhausted. The pressure gave rise to an increasingly conflicting climate between the teammates as well as a tense relationship with the coach. Francine was affected by the situation, especially since she clashed very hard with two partners who were also long-standing friends:

Despite the work I was doing with my sport psychologist, I was not there. It was difficult because we participated together in all the pre-Olympics training camps. I had to take it upon myself to just train and stay in control. When I arrived at the Olympics, I was in full decompression stage.

The OG were experienced in a balanced mood. Francine was disappointed not to perform better (ending 13th). She believed that she had had a good bout but she felt disturbed by a very high level of stress that prevented her, in her view, from finding the tactical solution that would have lead to victory.

\section{Sport saturation (28 years old)}

After the Olympics, Francine felt the need to have a break: 
I had been in the international circuit for a while and had experienced ups and downs in the course of my career. I had fought for Olympic selection for fourteen or fifteen months, participating in all the qualifying competitions. I needed something else. I needed to reverse my priorities. I needed to take care of myself and my personal life and to put fencing aside.

With her partner, she decided to have a baby and then to start fencing again:

I felt that I had not finished with fencing, that I still had something to do, something to prove to myself. Not necessarily with regard to competitive results, but I still wanted to learn and try new things. I decided to start fencing again and to continue until the next Olympics.

\section{Coming back to elite sports to prepare for the next OG (29 years old)}

Francine went back to training very early:

I went back to training 15 days after the delivery. I ran and cycled because I knew that I would have to be fully fit when restarting fencing training. I was pretty lucky because I had my baby at the end of June. Therefore I did not have any fencing training in July or August. Moreover, I did not have to work as I still had a full-time training arrangement. All that was perfect!

She went back to training with a feeling of being different to before:

When I went back to training, it was really to have fun. I still wanted intense experiences, I still wanted to learn. I relativised much more after the birth of my son. I stepped back better from what was happening to me.

Returning to fencing, Francine also resumed her psychological preparation. She expressed a major feeling of frustration after her first Olympics. For that reason, her goal was to participate in the next ones, despite her previous decision to terminate her sports career two years after the last OG. With her psychologist, she planned the following three years as 
follows: (a) regaining an international level, even if she did not qualify in major events, (b) achieving high results in major individual and team events, and (c) qualifying for the OG. Francine achieved good results during the first season. She even qualified for the national team for the European and World Championships.

Her statute of elite athlete and mother required strong organisation:

There are two different situations. Everyday life requires an organisation similar to that of every couple, that is: "Who takes the baby to nursery and who picks him up?" On the other hand, the organisation is different when I am away for a long time. Travel to Asia or the United States necessitates two-week absences. In such conditions, it is much more complicated for my husband to manage. His parents or my mother come to help him. We manage to organise something that suits everyone. The most important thing for me is to know that each one of them is fine. Otherwise, I fail in my competition as well as failing in my role as mother.

Regarding her family life, Francine indicated that she got a lot of support from her husband, who took charge of the baby during her long travels. She also described how she recorded videotapes in which she talked to her son, so that she felt the link would not be broken when travelling far away from home.

During this time she applied once again to enrol in the sport education course reserved for elite athletes and was successful.

At the end of the season, Francine said that she had a good feeling and was in control during fencing, including adapting new elements to the new rules. Nevertheless, although she felt very good during the team events, she experienced a lot of stress during individual events, where she performed less well.

During the pre-Olympic season, specific emphasis was also put on recovery. Francine said that she had improved her way of conserving her energy (e.g., taking more breaks, 
reducing intensity of the task when possible) in order to avoid too high a workload during training. The international circuit began with a third place, which convinced Francine that she could achieve her Olympic goal. She told her psychologist: "After this event, I know I can do it. I wasn't sure that I would be able to do it. But I can fence well”. The season continued with other good results in competitions but it became more and more difficult for Francine to perform well because of stress and fatigue. She trained hard and at the same time she was working hard for the competitive examination to becoming a sport administration civil servant. She also had to take care of the housework and her baby. Special schedule adjustments were made to relieve the sport load and allow Francine to prepare for the examination under good conditions. She eventually passed the examination with a very good score. Sport results in both European and World Championships were very similar to those of the preceding year, with Francine expressing difficulties with her fencing performance in the individual events but a very good commitment and performance during team events.

At the beginning of the Olympic season, Francine decided, in agreement with the national team coaches, to prepare alone and not in the national training centre any more. She wanted to be able to determine the workload by herself. Stress was very high between the chosen potential fencers. Francine achieved good results in World Cups but she failed to qualify for the OG. As she did not understand the decision, she applied to the National Olympic Committee but without success. She then decided to end her fencing career at once, instead of terminating her career at the end of the sports season as she had previously planned.

\section{Discussion}

This research used a holistic approach to explore the wave-like progress towards excellence of an elite female fencer involved in various life spheres (e.g., education, vocation, social life, motherhood) throughout the course of her sports career. Data gathered from Francine's elite athletic career emphasise the importance of an approach like that 
recommended by Wylleman and Lavallee (2004) when working in research, as well as with athletes, as a sport psychologist or sport psychology consultant. Francine's sports career, and more especially Olympic course, took place in a specific context which can help to explain the ups and downs of her path and which illustrates the singularity and non linearity of paths to excellence mentioned in recent research (e.g., Abott \& al., 2005; MacNamara \& al., 2010; Ollis \& al., 2006). In such a context, athletic transitions which framed the narrative of her path throughout her sports career appeared to be strongly linked to other domains of life. This result differed from that of Douglas and Carless (2006), who identified a dominant performance narrative type among female high level golfers. Finally, the way Francine managed each domain of her life and faced some sensitive, even crisis, transitions emphasises the relevance of psychological counselling throughout the sports career but also brings into question the conditions which would best contribute to the effectiveness of psychological intervention in enhancing both performance and personal growth.

\section{Importance of the context}

Francine's sport career developed within a socio-cultural and sport system context where athletes are advised to combine their sport and professional careers and to plan for a future after sport (Stambulova, Stephan, \& Jäphag, 2007). Moreover, fencing is an amateur sport with little financial support compared to professional sports where athletes may have the opportunity to earn large amounts of money. Such context may be taken into account when comparing athletes' experiences from one given study to another. Douglas and Carless (2009) found that two high-level professional female golfers tended to construct their identity almost exclusively through golf performance. Francine qualified one stage of her path as a stage of priority to sport career, and transitions she identified as highly significant in the course of her life were almost all athletic transitions. When talking about this stage and the main transitions, she included sport each time, but also events or situations related to other domains of her life. 
Nevertheless, when looking back at the way in which her career developed, it appears that at each level of her development (e.g., sport, education, social life) she rarely took into account the interactive and interdependent nature of these different developmental contexts. This meant that she had major concurrent changes just before the OGs, requesting transitions at the educational level at the same time as requiring training and qualifying competitions for the OGs. To increase the probability of success in major competitions such as OG, the development of athletes' personal paths for education and professional insertion should be planned well in advance, taking the major stages of their sport career into account.

Another characteristic of the French fencing context is that the best athletes are systematically grouped together in a training centre specific to a given weapon as well as category (i.e., junior, elite). Francine adapted well to the junior foil-training centre, situated not far from her family home. In contrast, she failed to adapt to the elite foil-training centre. Her entry coincided with a normative athletic transition from junior to senior. As Francine only mentioned competitive stress, the psychologist put forward the hypothesis that stress may be due to that normative transition which is often described as sensitive because athletes move from the junior category, where they feel like top-level athletes, to the senior one. They would like to go directly to the top in the senior category but they are unable to do so due to the larger group size as well as a wide age bracket and more experienced athletes (e.g., Wylleman \& Lavallee, 2004). Of course, the stress faced by Francine may have been due in part to this transition from junior to senior. But Francine's narrative from the retrospective interview suggested that other factors may have played a significant role in her decision to withdraw from foil, even though these were not mentioned during follow-up interviews: the feeling of well-being she had experienced in the junior training centre, difficulties encountered in the transfer from one university to another, and homesickness reinforced by the long distance of the centre from the family home. The crisis transition she then 
experienced had severe consequences on her Olympic path as it prevented her from getting a possible first Olympic experience, which would have been at the optimal age (i.e., 24 years old), if she had remained on the international circuit. This case emphasises the limits of systematic integration into a national training centre and the relevance of allowing other possible routes (e.g., clubs, private structures), taking into account athletes' individual cases.

In the case of Francine, the fencing context had a positive impact on Francine's sports career, with the introduction of the female sabre as an official competitive event which occurred the year Francine decided to withdraw from fencing. Thanks to the introduction of this new weapon for female athletes, and with the support of the club's teammates when Francine came back home, she found a new source of enjoyment in sport and quickly renewed her competitive commitment. Finally, the density of elite athletes in a national team who can seek Olympic qualification can also impact on the degree of success in the sports career. The case of Francine emphasises how hard Olympic preparation can be when competing in a sport where there are more potentially qualified athletes than possible qualifications for the OG. France has always been a very competitive nation in fencing with numerous World and Olympic champions or medallists. This lasting success rests in part on the high density of very talented fencers training together throughout the year. In such a context, training together while at the same time competing against each other for an Olympic qualification, constitutes a crucial barrier to overcome and often gives rise to an increasing feeling of pressure until the final selection decision. In the case of Francine, the first Olympic qualification course was experienced as exhausting due to both demanding rules for qualification (i.e., being in the international Top 8) and increasing tension and conflict within the training group. The second Olympic qualification course ended in failure to be qualified, despite very good performances but in a context of very strong competition between members of the national team. In such a context, qualifying is almost as important as performing in OG. The period from qualification 
to the Olympic event is then a very sensitive one as regards finding the psychological balance between recovering from the pressure experienced during the qualifying period and the need to keep fully focused on the Olympic goal. Francine benefited from the psychologist in that respect (i.e., recovering, focusing on the Olympic goal), but her case leads us to question the degree of efficacy of such intervention when the psychologist doesn't have the opportunity to support the athletes to the very end when pressure is greatest, namely, during the pre-Olympic camps and the Olympics. Finally, for those who do not qualify, psychological work may need to be undertaken to help athletes to relativize their failure in view of the high level of competition within the national team and to help them to plan the future, whether as an elite athlete or as a retired athlete for those at the end of their sports career.

\section{Stages and transitions}

In previous studies, optimal athletic achievement is often considered to be the entire life focus of top performers for whom "it is impossible to be much else" (Werthner and Orlick, 1986, p.337). In contrast, when talking about her path, Francine described three stages, of which only one focused solely on the sports career. Her personal balance or well-being appeared to be strongly related to her psychosocial development including, in particular, family (i.e., mother, husband, son) and teammates. With regard to Schlossberg's (1981) model of transitions, the adaptation to athletic career transitions depends largely on the availability of social support. In the case of Francine, social life and relationships were visible all along her sports career experience, either in a positive way (e.g., feeling of stability due to living as a couple, feeling of maturity and well-being due to motherhood, achieving better performance when in team events), or a negative way (e.g., pressure from perceived performance expectations of others, stress and disappointment due to the clash with teammates just before the OG, feeling of injustice when not supported by the federal staff in her education project). The pre-Olympic period appears to be a sensitive one regarding inter- 
personal relationships within the team (e.g., McCann, 2008). The OG is a unique competition (e.g., specific rules for qualification, four-year cycle, media dimension) and stakes are particularly high for coaches as well as athletes (e.g., institutional expectations, media comments, main goal of a career). In such a specific context, psychological preparation of the coaching staff may be as important as individual psychological preparation for the team in terms of contribution to an adaptive motivational climate.

Francine's trajectory also showed an alternation between positive transitions, crisis transitions, and coping strategies. With regard to Stambulova's (2000) categorization of coping strategies for facing crisis situations, on three occasions Francine chose to use a rejection strategy consisting of: (a) withdrawing from fencing when failing to adapt to the elite foil-training centre, (b) withdrawing from sabre to become a mother when experiencing sport saturation after the Olympics, and (c) advancing her sport career termination when she failed to qualify for the following Olympics. Finally, the successive changes in her education pathway resulted in the extension of the overlap between her academic and athletic developments for a long period (i.e., from the age of 19 to the age of 30). Moreover the consequences of her choices (e.g., police training college which lead to overworking, a competitive examination just before the OG) may have had a negative impact on her feeling of fitness and well-being when nearing the date of the Olympics. In comparison, a study carried out on medal-winning athletes in Olympic Games or World Championships (DurandBush \& Salmela, 2002) showed that those engaged in university education had broken off their studies from the year preceding the OG in order to concentrate all their efforts on that event. Thus, Francine's singular trajectory with its many influences during her sports career illustrates the importance of working with elite athletes from a complete lifespan perspective (Wylleman and Lavallee, 2004). It also brings to the fore the delicate balance which has to be maintained to reconcile all spheres of life. 


\section{Limitations}

The present study has both sample and assessment limitations that restrict its generalizability. Regarding the sample, the purpose of the study was to examine a specific case without the intention of trying to represent the population. Regarding the assessment, using a retrospective interview could be a limitation of this study, as it could cause a recall bias (e.g., Kerr \& Dacyshyn, 2000). But this limitation is likely to be reduced by the use of handwritten notes taken by the sport psychologist during in vivo interviews at the time most transitions were being experienced by Francine. Another limitation of the study lies in the need to preserve the anonymity of the athlete, even if she agreed to participate as a single case in the study. As Mellick and Fleming (2010) pointed out, the use of autobiographical narrative with elite athletes makes it difficult to guarantee anonymity, notably when the athlete in question has won world or Olympic medals. In this study, the coach and teammates implicated in the story of Francine could be recognised, despite the removal of all dates and places. For this reason, narrative referring to these others has deliberately not been deeply developed, with the aim of avoiding more details in the story, which could permit their identification.

\section{Conclusion and further research}

Even if examination of Francine's sports career brings out commonly described transitions (e.g., Bloom, 1985; Stambulova, 1994, 2000) from initiation to elite sport, her trajectory appears to be singular, especially when withdrawing from foil with the intention of never going back to elite sport, and then starting a new elite sport career in sabre. Moreover, the nonlinear nature of the pathway suggested by Abbott et al. (2005) fits well with Francine's wave-like pathways of both sports career and educational development. With such an uncertain path, regular psychological follow up appears useful to help athletes successfully negotiate sensitive transitions, thanks to the opportunity it gives them to talk about their life, to communicate a sense of their previous experiences to others and, in this way, to maintain a 
coherent identity and sense of self (e.g., Carless \& Douglas, 2008; Crossley, 2000; Douglas \& Carless, 2009). The question, as an applied sport psychologist, is then to find the balance between accompanying athletes at each turning point of their path and working in advance, as soon as they entire high level sport to help them avoid negative transitions as much as possible. It should be noted that in France the fencing federation appears to be a precursor regarding the psychological assessment of talented young fencers, with aim of helping them to adapt well when entering a training centre. Nevertheless, and whatever the sport, for a long time training centres have lacked a full time sport psychologist or at least a career adviser dedicated to athletes. In the present case study, when Francine asked for a psychological preparation one year before her first $O G$, with a request focused on performance enhancement, she had already experienced several ups and downs in her sport as well as educational development. When looking at the following Olympic period, Francine appeared to still be encountering difficulties finding a balance reconciling all areas of her life. Even if the psychological work during the five last years of her sports career was useful, looking at most of Francine's performances and the duration of that voluntary psychological collaboration, early planning of both expected sports career and professional future, as well as an earlier psychological preparation may have given Francine more stability throughout her sports career and probably more trust for coping with stress during Olympic stages. The questions are then to identify when to begin such work and how to build trust to encourage athletes to use the psychological support.

This case study illustrates the importance of carrying out more research on the role and influence of non athletic transitions which may affect the sport career, especially during the Olympic stage which carries high pressure due to its very specific context. It also emphasises the importance of adopting a culturally specific approach (e.g., French law on elite sport training/education, sport organisation with elite training centres) in research, to better 
understand the multidimensional nature of transitions. Finally, it brings to the fore the importance of anticipating and planning normative athletic as well as non athletic transition experiences as early as possible to reach the Olympics in the best condition.

\section{References}

Abbott, A., Button, C., Pepping, G-J., \& Collins, D. (2005). Unnatural selection: Talent identification and development in sport. Nonlinear Dynamics Psychology and Life Sciences, 9, 61-88.

Baltes, P. (1987). Theoretical propositions of life span developmental psychology: On the dynamics between growth and decline. Developmental Psychology, 23, 611-626. doi:10.1037/0012-1649.23.5.611

Bloom, B.S. (1985). Developing talent in young people. New York, US: Ballantine.

Carless, D., \& Douglas, K. (2008). Narrative, identity and mental health: How men with serious mental illness re-story their lives through sport and exercise. Psychology of Sport and Exercise, 9, 576-594. doi: 10.1016/j.psychsport.2007.08.002

Côté, J. (1999). The influence of the family in the development of talent in sport. The Sport Psychologist, 13, 395-417.

Côté, J., \& Hay, J. (2002). Children's involvement in sport: A developmental perspective. In J.M. Silva \& D. Stevens (Eds.), Psychological foundations in sport (2 ${ }^{\text {nd }}$ ed., pp. 484502). Boston, US: Merrill.

Crossley, M. (2000). Introducting narrative psychology: Self, trauma and the construction of meaning. Buckingham, UK: Open University Press.

Douglas, K., \& Carless, D. (2006). Performance, discovery, and relational narratives among women professional tournament golfers. Women in Sport and Physical Activity Journal, $15,14-27$. 
Douglas, K., \& Carless, D. (2009). Abandoning the performance narrative: Two women stories of transition from professional sport. Journal of Applied Sport Psychology, 21, 213-230. doi: 10.1080/1041320090295109

Durand-Bush, N., \& Salmela, J.H. (2002). The development and maintenance of expert athletic performance: Perceptions of world and Olympic champions. Journal of Applied Sport Psychology, 14, 154-171. doi: 10.1080/10413200290103473

Kerr, G., \& Dacyshyn, A. (2001). The retirement experiences of elite, male gymnasts. Journal of Applied Sport Psychology, 12, 115-133.

MacNamara, A., Button, A., \& Collins, D. (2010). The role of psychological characteristics in facilitating the pathway to elite performance. Part 1: Examining environmental and stage-related differences in skills and behaviors. The Sport Psychologist, 24, 74-96.

McCann, S.C. (2008). At the Olympics, everything is a performance issue. International Journal of Sport and Exercise Psychology, 6, 267-276. doi:

$10.1080 / 1612197 X .2008 .9671871$

Mellick, M., \& Fleming, S. (2010). Personal narrative and the ethics of disclosure: a case study from elite sport. Qualitative Research, 10, 299-314. doi:

$10.1177 / 1468794110362873$

Ollis, S., MacPherson, A., \& Collins, D. (2006). Expertise and talent development in rugby referees: An ethnographic enquiry. Journal of Sport Sciences, 24, 309-322. doi: $10.1080 / 17461390500188710$

Palmer, F., \& Leberman, S. (2009). Elite athletes as mothers: Managing multiple identities. Sport Managemnet Review, 12, 241-254. doi: 10.1016/j.smr.2009.03.001

Petitpas, A., Champagne, D., Chartrand, J., Danish, S., \& Murphy, S. (1997). Athletes guide to career planning. Champaign, IL: Human Kinetics. 
Rosnet, E. (2005). Intérêts, difficultés et enjeux de l'évaluation psychologique des sportifs [Interest, difficulties and challenges of athetes' psychological assessment]. Bulletin de Psychologie, 58, 113-117.

Rosnet, E., Le Scanff, C. \& Heuzé, J.P. (2003). Evaluation des besoins et des objectifs de la préparation mentale [Evaluation of needs and goals for mental preparation]. In C. Le Scanff (Ed), Manuel de Psychologie du Sport: l'intervention auprès du sportif [Manual of sport psychology: intervention with athlete] (pp.15-64). Paris, FRA: Revue EPS.

Schlossberg, N. K. (1981). A model for analysing human adaptation to transition. The Counseling Psychologist, 9, 2-18. doi: 10.1177/001100008100900202

Schlossberg, N. K. (1984). Counseling adults in transition: Linking practice with theory. New York, US: Springer.

Sharf, R.S. (1997). Applying career development theory to counselling. Pacific Grove, CA: Brooks/Cole.

Sinclair, D. A., \& Orlick, T. (1993). Positive transitions from high-performance sport. The Sport Psychologist, 7, 138-150.

Stambulova, N. (1994). Developmental sports career investigations in Russia: a postperestroika analysis. The Sport Psychologist, 8, 221-237.

Stambulova, N. (2000). Athletes' crises: A developmental perspective. International Journal of Sport Psychology, 31, 584-601.

Stambulova, N., Alfermann, D., Statler, T., \& Côté, J. (2009). ISSP position stands: career development and transitions of athletes. International Journal of Sport and Exercise Psychology, 7, 395-412. doi: 10.1080/1612197X.2009.9671916 
Stambulova, N., Stephan, Y., \& Jäphag, U. (2007). Athletic retirement: A cross-national comparison of elite French and Swedish athletes. Psychology of Sport and Exercise, 8, 101-118. doi: 10.1016/j.psychsport.2006.05.002

Taylor, J., \& Ogilvie, B. (1994). A conceptual model of adaptation to retirement among athletes. Journal of Applied Sport Psychology, 6, 1-20. doi: $10.1080 / 10413209408406462$

Thomas, J.R., \& Nelson, J.K. (1996). Research methods in physical activity. Champaign, IL: Human Kinetics.

Wapner, S., \& Craig-Bay, L. (1992). Person-in-environment transitions: Theoretical and methodological approaches. Environment and Behavior, 24, 161-188.

Werthner, P., \& Orlick, T. (1986). Retirement experiences of successful Olympic athletes. International Journal of Sport Psychology, 17, 337-363.

Wylleman, P., \& Lavallee, D. (2004). A developmental perspective on transitions faced by athletes. In M.R. Weiss (Ed.), Developmental Sport and Exercise Psychology: a lifespan perspective (pp. 503-523). Morgantown, WV, US: Fitness Information Technology.

Wylleman, P., Alfermann, D., \& Lavallee, D. (2004). Career transitions in sport: European perspectives. Psychology of Sport and Exercise, 5, 7-20. doi: 10.1016/S14690292(02)00049-3 